\title{
Developing E-society Cognitive Platform Based on the Social Agent E-learning Goal Oriented
}

\author{
Jamal Raiyn \\ Computer Science Department, Al-Qasemi Academic College of Education, Baqa Alqarbiah, Israel \\ E-mail: rayan@qsm.ac.il \\ Received January 27, 2011; revised March 1, 2011; accepted March 22, 2011
}

\begin{abstract}
In this paper we introduce the e-society cognitive approach based on the social agent. The social Agent is e-learning oriented. The e-society cognitive platform may consider different fields like e-learning, e-health, e-commerce, e-medicine, and e-government. In this paper we will introduce the e-society platform. The e-society platform supports the educational and pedagogical aspects. The e-society is based on the agent technologies. The social agents offer impressive, meaningful and several features as autonomy, manage negotiation, and make decision. The e-society cognitive platform consists of three main layers: social agents, beliefs, and tools for application layer. The goal of the e-society platform is to increase the perceiving of the transportation education in the school.
\end{abstract}

Keywords: E-society, E-learning, Social Agent

\section{Overview}

From technology tools viewpoint this paper presents new powerful technology tools based on the use of the adaptive autonomous social agents. The autonomous social agents use interactive simulations to facilitate communication skills of the users in the e-society. An adaptive autonomous social agents based on the interactive simulation differs from traditional kinds of technology in that the simulated entities are modeled in terms of agents, as it explicitly attempts to model specific behaviors of specific individuals. The autonomous social agents are able to take initiative and exercise a non-trivial degree of control over its own action, and the autonomous social agents accept high-level requests indicating what a human wants and are responsible for deciding how and where to satisfy the request. Furthermore the autonomous social agents may learn in some circumstances from past occurrences. The use of autonomous social agent technology in the e-society cognitive platform will lead to significant changes in the meaning of the e-society field and will offer impressive environments in which the user has great possibilities of interaction. For the definition of the autonomous social agents, there are no absolutely world-wide accepted definition, and a clearly definition seems impossible. However, there are many definitions which are, usually, based on the functions and behaviors the agent under the domain consideration, which means, an agent can be defined operationally in term of the environment in which they provide their services. Franklin and Graesser (1996) [1] define an autonomous agent that senses their environment and acts on it. Wooldrige and Jennings (1995) [2] write in reactive agents that perceive their environment and response in a timely fashion to changes that occur in the environment, in other words, whose behavior is determined as a result of a reasoning process based on beliefs and desires. Russell and Norvig (1995) [3] write an agent is something that perceive and act rational to achieve his goal based on both its own experience and the built-in knowledge used in constructing the agent for the particular environment in which it operates. In this paper we aim to develop the e-society that is focused on educational transportation. Traffic accident is result of many different interacting factors (Jacobs, Sayer, 1982) [4], all of which can be summed up into two categories: For at least the last forty years the industry countries of Western Europe and North American have had to acknowledge the fact that road accidents are a prime cause of death and injury. Over this period substantial sums of money have been spent on trying to contain what is clearly a serious health problem. Approximately 46000 Americans are killed in motor vehicle accidents each year, and four million are injured, about 100000 of them severely. In recent 
years there have been two major studies of causes of death worldwide which have been published in the "Global Burden of Disease" (1996, World Health Organization, World Bank and Harvard University) and in the "World Health Report -Making a Difference" (WHO 1999). These publications show that in 1990 road accidents as a cause of death or disability were by no means insignificant, lying in ninth place out of a total of over 100 separately identified causes. However, by the year 2020 forecasts suggest that as a cause of death, road accidents will move up to sixth place and in terms of years of life lost and “disability adjusted life years" (DALYs) will be in second and third place respectively [5]. In Israel, the number of the motor vehicle accidents in the Arabic sector is double compared to the number of the motor vehicle accidents in the Jews sector. Focused on the above illustrated statistical analyses of the accident, and based on the core technology of the cognitive social agents we aim to create the e-society cognitive platform.

The major goal of the e-society cognitive platform is to develop a novel learning strategies to improve the behavior of the people in the society. The paper is organized as follow. Section 2 introduces the e-society vision and architecture. Section 3 describes the e-society elearning environment tools. Section 4 concludes the paper.

\section{E-society Cognitive Vision}

E-society is a cognitive platform. The e-society platform is based on the agent technologies [6]. The agents can manage negotiation, make decision, and handle autonomy without interaction of the users. The major goal of the e-society based on the STSTE is to reduce vehicle accidents in the children environment.

\subsection{STSTE}

STSTE stands for Society Technology Science Transportation Education. In the context of STSTE, the goals of teaching and learning are largely directed towards engendering cultural and democratic notions of scientific literacy. Here, advocates of STSTE argue that in order to broaden students understanding of science, and better prepare them for active and responsible citizenship in the future, the scope of science education needs to go beyond learning about scientific theories, facts and technical skills. Therefore, the fundamental aim of STSTE is to equip students to understand and situate scientific and technological developments in their cultural, environmental, economic, political and social contexts. Furthermore to create a modern and civilize character of students that can perceive environmental changing world wide and adapt autonomously. STSTE aims to develop the following skills and perspectives:

- Social responsibility;

- Critical thinking and decision making skills;

- The ability to formulate sound ethical and moral decisions about issues arising from the impact of science on our daily lives;

- Knowledge, skills and confidence, to express opinions and take responsible action to address real world issues in science.

\subsection{E-Society Platform Architecture}

In our research project that is running in the e-society laboratory at the alqasemi academy, we use the autonomous agent based interactive simulation to create e-society platform that extends the currently used technology tools in order to access different resources in the e-society. E-society is a general term that includes different technology resources as e-learning, e-commerce, e-medicine, and e-government that are essential for human. The autonomous agent aims to enable the human to join the modern technology resources. In general the architecture of the autonomous agent consists of three main components as illustrates in Figure 1.

1) Agent Layer: The agent layer is housing in the agent environment that includes agents with different tasks, e.g., representation agent which performs directed communication with the user, in real-time (synchrone technology), to represent and discuss the material and behavior of the technology resource. The analyst agent is in charge of making analysis and submitting the report about the user at the end. The analysis is based on the monitoring the actions of the user in the simulation or even on the job, the agent is able to determine where the

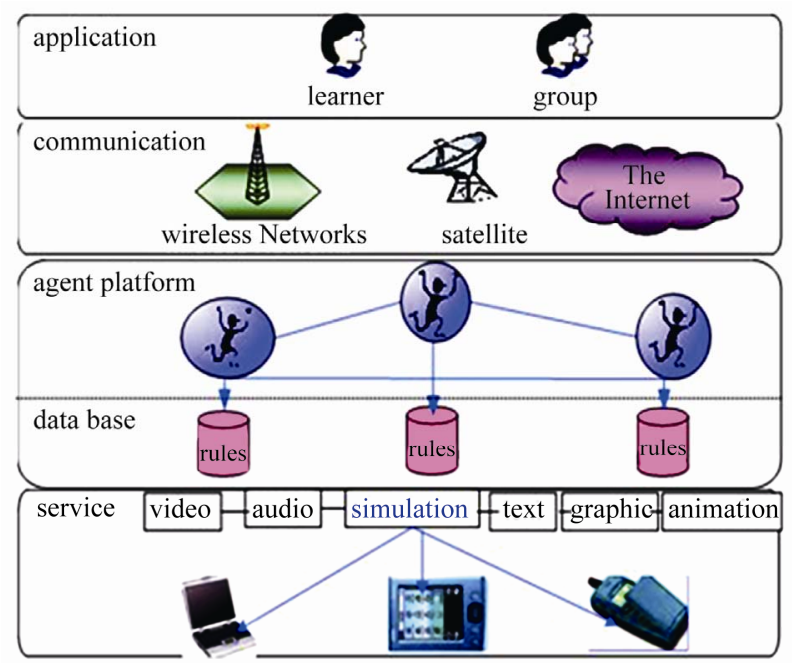

Figure 1. E-society core technology. 
user understands concepts and processes imperfectly and provide appropriate and timely advice.

2) Application Layer: All user activities will occur over the user interface. The learner can establish contact to the autonomous agent per text or voice interface based on web application.

3) Communication Layer: This layer is responsible for the communication between user and agent system and between the agents.

The e-society environment supports different mobile devices like notebook, mobile phone, PDA. In addition the e-society offers different learning strategies.

\subsection{E-society Characteristics}

The characteristics of the e-society cognitive platform are summarized as follows:

E-education: The e-society platform uses simulation tools for self-learning. The goal of the simulation is to teach the students how to learn.

Creatively thinking: The social agent communicates and updates its knowledge permanently. This is a good reason that the e-society rules is not fixed and can be able developed all the time. This is the essence behind this objective and that aims to educate students to enable them to think creatively.

E-pedagogical: E-pedagogy is expressed by the relation between teaching and learning. Teaching can be observed. Learning takes place inside the individual person.

Self-feedback: Educating students through different teaching methods is to equip them with the ability to criticize the material and reflect on it with regard to their own practical experience. This kind of virtual experience can be transferred to real life practice.

E-society mobility: The e-society platform can be browsed on different mobile devices.

\section{E-learning Environment}

The e-society environment supports various e-learning technology tools. Some tools are used for synchrone distance learning. The synchrone distance learning tools enable communications between teacher and learners. Other distance learning tools are asynchronous.

Elluminate: Ellumiante is one of the synchrone distance leanring tool. Figure 2 illustrates the elluminate e-learning environment tool. This technological tool is used for real-time e-learning. The teacher communicates with the students at the same time however in different geographic places. The elluminate supports many functions for teachers also for students. The functions are expressed in browsing internet pages, sending files, running multimedia tools, and shared computer program.

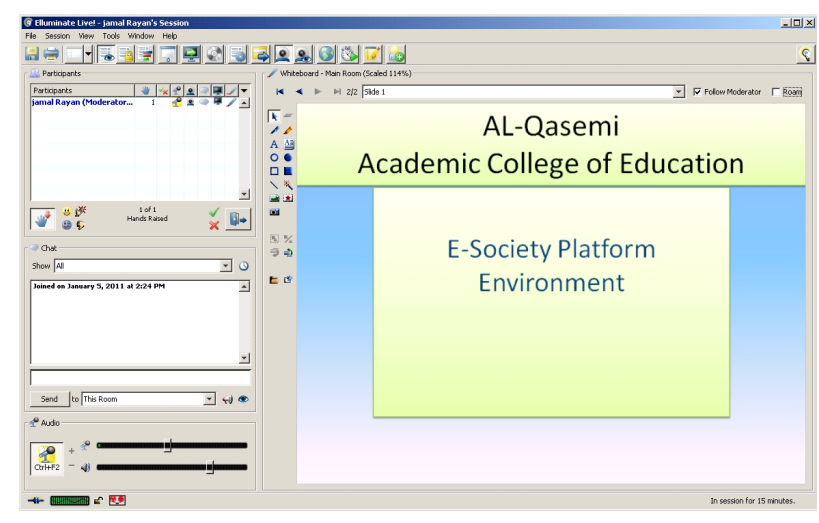

Figure 2. Elluminate technology.

Facebook: we have selected to implement the facebook in the e-society platform, because now the facebook is the most of technology tools that is used by students.

Mobile Devices: the e-society cognitive platform is adaptive to different display sizes. And the e-society can run in various mobile devices. Figure 3 illustrates that the e-society is supported by the mobile phone.

\subsection{E-society for Transportation Education}

The major tasks of the autonomous agent are to present and explain the material for the user in optimized and utilized form. The autonomous agent may use multimedia, third dimension environment in comprehensive, and simply form to present the learn material. Hence, the e-society manages negotiation with the users to deal with their questions and comments. At the end, the e-society submits report that includes analysis and evaluation of each user. Based on the analyzed information, it will be known which kinds of disabilities have the user. It will be presented some assistive technology tools in java applets which describe the autonomous agent behaviors in specific cases. E-society is becoming more and more important with the improvements in assistive technologies such as broadband internet access and multimedia communication based on Quality of Service Parameters. Agent technologies aim to improve human behavior. Based on the last published studies that is made difference between the electronic textbooks for boys and girls (students and children). We aim to develop the autonomous agent to implement emotional sounds that make different by dealing with boys and girls. Based on the analysis of the collected information from the users, the e-society can make prediction. Furthermore, the e-society can submit report to improve the lack of the currently running dialog.

\subsection{E-society Future Vision}

To implement the transportation education area in the 


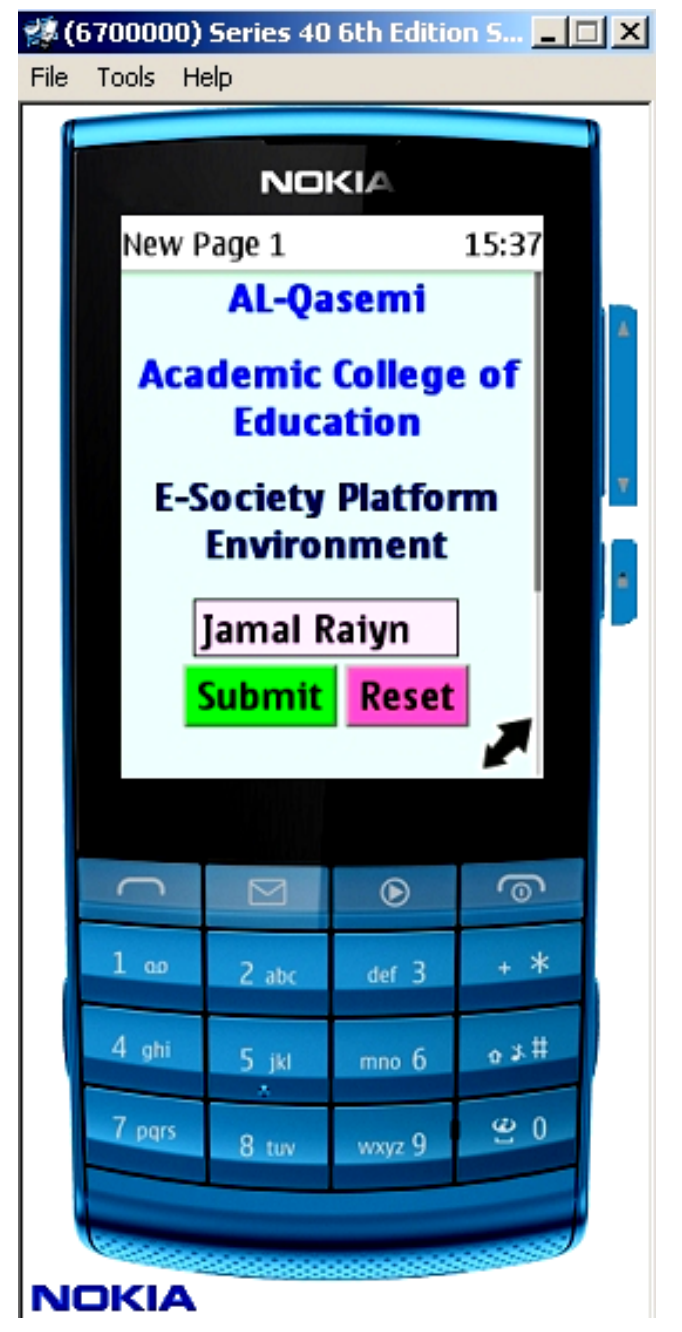

Figure 3. E-society mobility.

e-society platform, we aim to develop new technology tools that are focused in the transportation education. The e-society cognitive platform aim to develop new learning tools for transportation education area as following:

1) Applying the multimedia and graphic tools in the transportation education.

2) Applying the simulations based on real cases from the transportation area.

3) Developing and applying new pedagogical initiative in the schools (from kindergarten till high school).

4) Developing new learning tools for the didactica in the transportation education area.

\section{Conclusions}

Actually, the learning strategy in alqasemi college is basically based on traditional learning strategy, i.e., face- to-face interaction in tradition (physical) classroom. In the last few years the college began to provide some online courses. As a result of the satisfaction of our students about online courses, we are interested to develop the e-society platform to implement new e-learning tools. Based on this e-society platform, many courses can be created that are specialized in different areas, such as in mathematics, computer science, environmental, and transportation fields. Furthermore, in the future, the e-socierty platform's functions can be enlarged to integrate new e-learning tools for all schools level. In special case study we have used the e-society for human interaction. The basic idea of this study is to create the basis for a virtual forum and meeting for students and society member to exchange opinions dissimilarity in different fields. The e-society platform is considered important and necessary tools for dialog improvement and help to draw near between the society members. In future work we plan to modify the e-society to include different society fields.

\section{Acknowledgements}

This study was funded by a grant from the Unit for Research in the Alqasemi College.

\section{References}

[1] S. Franklin and A. Graesser, "Is It an Agent, or Just a Program: A Taxonomy for Autonomous Agents," Proceedings of the $3^{\text {rd }}$ International Workshop on Agent Theories, Architectures, and Languages, Heidelberg, August 1996, pp. 1-10.

[2] M. Wooldridge and N. R. Jennings, "Intelligent Agents: Theory and Practice," The Knowledge Engineering Review, Vol. 10, No. 2, 1995, pp. 115-152.

[3] S. Russell and P. Norvig, "Artificial Intelligence: A Modern Approach,” Prentice Hall, Englewood Cliffs, 1995.

[4] G. D. Jacobs and I. Sayer, "Road Accidents in Developing Countries,” Accident Analysis \& Prevention, Vol. 15. No. 5. 1983, pp. 337-353.

[5] M. P. Salmon and G. M. Lenne, "Systems-Based Human Factors Analysis of Road Traffic Accidents: Barriers and Solutions," Australasian Road Safety Research, Policing and Education Conference, Sydney, 10-13 November 2009, pp. 418-426.

[6] B. Chen and H. Cheng, "A Review of the Applications of Agent Technology in Traffic and Transportation Systems," IEEE Transactions on Intelligent Transportation Systems, Vol. 11, No. 2, June 2010, pp. 485-497. doi:10.1109/TITS.2010.2048313 